\title{
SYNTHESIS OF GOLD NANOSTRUCTURES USING WET CHEMICAL DEPOSITION IN $\mathrm{SiO}_{2} / \mathrm{Si}$ TEMPLATE
}

\author{
V.D. Bundyukova ${ }^{a}$, D.V. Yakimchuk ${ }^{\text {a }}$, A. Kozlovskiy ${ }^{\text {b,c }}$, D.I. Shlimas ${ }^{\text {b,c }}$, \\ D.I. Tishkevich ${ }^{\text {a, d }}$, and E.Yu. Kaniukov ${ }^{\mathrm{e}}$ \\ ${ }^{a}$ Scientific-Practical Materials Research Center of National Academy of Sciences of Belarus, 19 P. Brovka Street, \\ 220072 Minsk, Belarus \\ ${ }^{\mathrm{b}}$ Laboratory of Solid State Physics, Institute of Nuclear Physics, 2/1 Abylay Hana Avenue, 010008 Astana, Kazakhstan \\ 'L.N. Gumilyov Eurasian National University, 2/1 Abylay Hana Avenue, 010008 Astana, Kazakhstan \\ d South Ural State University, 76 Lenin Avenue, 454080 Chelyabinsk, Russia \\ ${ }^{\mathrm{e}}$ Institute of Chemistry of New Materials of National Academy of Sciences of Belarus, 36 Francyska Skaryny Street, \\ 220141 Minsk, Belarus \\ Email: victoria.bundyukova@gmail.com
}

Received 6 May 2019; revised 6 June 2019; accepted 30 September 2019

\begin{abstract}
The size and interposition of particles is a key parameter for the practical application of metallic nanostructures which requires the development of a synthesis method with precise control over their parameters. In this work the method for the synthesis of gold nanostructures in the pores of silicon dioxide from a gold sulfite complex and a gold chloride solution via wet chemistry technique was proposed. The influence of deposition parameters, such as deposition temperature and electrolyte composition, on the deposit morphology was studied. It was shown that gold agglomerates were unevenly distributed over the silicon surface at high temperatures and practically uniformly distributed with temperature decrease. Addition of fluoric acid at the deposition stage defines the metal precipitation selectivity into the silicon oxide pores. The peculiarities of gold nanostructures formation mechanism were discussed.
\end{abstract}

Keywords: porous $\mathrm{SiO}_{2} / \mathrm{Si}$ template, wet chemistry, growth mechanism, gold nanostructures

PACS: $61.46 .+\mathrm{W}$

\section{Introduction}

The steady increase in the number of publications devoted to nanostructures (NSs) and nanostructured materials is due to their unique properties, which are not typical for the bulk objects of the same composition [1, 2]. Particular attention is paid to NSs made of plasmonic metals, such as copper, silver and gold, exhibiting their unique optical properties in the visible wavelength range [3, 4 ]. When a light wave interacts with an NS with characteristic dimensions smaller than the wavelength of light, an oscillation of electronic cloud with plasmonic frequency $\omega p$ arises at the metal/dielectric interface (most often the di- electric is air) [5]. These areas are characterized by a high electrical field intensity - 'hot spots' [6. This peculiarity makes it possible to use these structures as the basic element for signal enhancing in surfaceenhanced Raman spectroscopy (SERS) for the study of substances with low concentrations [⿰].

The optical properties of plasmonic NSs strongly depend on the size, shape and type of metal [8]. These parameters determine the position and intensity of the plasmon resonance, the knowledge of which is required for laser type selection for SERS research. The shape and size of particles depend on the synthesis parameters, such as concentration and temperature of active solutions, deposition time, 
etc. [9, 10]. Using of the template synthesis method allows one to effectively control the deposition of NSs by varying the listed parameters [11-15]. Thus, in recent works we have demonstrated the possibility of obtaining copper [16] and silver NSs [17, 18] with a different size and shape in the pores of the ion-track $\mathrm{SiO}_{2} / \mathrm{Si}$ template. Appearance of an oxide film on the silver and copper NSs surface limits their service durability due to blocking plasmonic effects. Considering the fact that gold based NSs are void of such problem [19-21], in this work an attempt of gold NSs selective deposition in the pores of the $\mathrm{SiO}_{2} / \mathrm{Si}$ template is made. To obtain the NSs, the technique described in [22] was taken as the basis. Also, the first experiments on gold NSs deposition into a porous template from a solution of gold chloride were carried out. The deposition mechanism is not fully understood, especially with respect to Au cations and $\mathrm{Cl}$ anions. The authors proposed the gold NSs production in the pores of a polymer ion-track template by using a gold sulfite complex solution [23. It should be noted that it is difficult to use systems with gold NSs in the polymer template pores for SERS application, since the polymer has a large number of molecular bonds, which introduce a lot of additional background peaks in SERS spectra. There are no difficulties with interpreting obtained results when silicon templates are used, since such substrates give only one strong vibration mode in the region of $520 \mathrm{~cm}^{-1}$.

Thus, the possibility of synthesizing gold NSs in pores of silicon oxide from a gold sulfite complex and a gold chloride solution under various deposition conditions, as well as a detailed study of the obtained NSs are considered in the paper.

\section{Methods}

For deposition of gold $\mathrm{NSs}_{\mathrm{SiO}} / p$-Si templates with pore sizes in the silica layer of about $550 \mathrm{~nm}$ were used. The features of obtaining such templates are described in detail in [24-27]. The deposition of gold into $\mathrm{SiO}_{2}$ pores was carried out by the means of wet chemistry from the gold (I) sulfite complex $(\mathrm{Na})\left[\mathrm{Au}\left(\mathrm{SO}_{3}\right)_{2}\right]$ prepared according to the methods [22] and a gold chloride solution $\mathrm{AuCl}_{3} \cdot \mathrm{H}_{2} \mathrm{O}$. The temperature of the solution was 0,25 and $50^{\circ} \mathrm{C}$. The deposition was carried out with the addition of a $5 \mathrm{M}$ solution of hydrofluoric acid (HF) to the gold
(I) sulfite complex and the gold chloride solution in a ratio of 1:1.

The primary attestation of the deposition results was carried out on a scanning electron microscope (SEM, Hitachi TM3030) with an attachment for energy dispersive X-ray spectroscopy studies (EDX, Bruker XFlash MIN SVE). A detailed analysis of the morphology of gold NSs was carried out on a SEM JEOL JSM-7500F.

\section{Results and discussion}

Figure 1 shows gold NSs deposited at various temperature conditions.

The increase of the gold amount on the surface of the $\mathrm{SiO}_{2} / \mathrm{Si}$ template with electrolyte temperature decrease is clearly visible on SEM images (Fig. 1 (a, $\mathrm{d}, \mathrm{g})$ ) obtained from a large sample area. At $50^{\circ} \mathrm{C}$ single gold agglomerates are formed on the surface, and most of pores remain unfilled (Fig. 1 $(a, b, c)$. The temperature decrease down to $25^{\circ} \mathrm{C}$ leads to a metal amount increase on the surface of $\mathrm{SiO}_{2}$, as well as to the formation of gold particles in the pores of $\mathrm{SiO}_{2}$ (Fig. 1 $(\mathrm{d}, \mathrm{e}, \mathrm{f})$ ). Sodium-containing crystals are also present on the surface. Gold NSs have characteristic sizes less than $100 \mathrm{~nm}$ and are randomly distributed on the template. Further temperature lowering down to $0^{\circ} \mathrm{C}$ causes an even greater increase in the metallic phase amount formed on the surface and in the pores (Fig. 1 (g, h, i)). This gold deposit is formed both in the form of separate crystallites with sizes up to $200 \mathrm{~nm}$, and their agglomerates. The analysis of EDX-maps and their corresponding spectra indicates the presence of only gold, silicon and oxygen (from $\mathrm{SiO}_{2}$ ) in the studied systems.

Using a gold sulfite complex, deposition of gold in individual pores can be carried out provided that the temperature of the solution will be low. But because of the agglomerates formation on the surface it is not possible to achieve selectivity of the process. Therefore, when using a gold sulfite complex without additional activation of a silicon substrate localized on the bottom of pores in an oxide layer, the selectivity (exclusively in the pores) of the metal deposition process will be low.

For chemical activation of the silicon surface, hydrofluoric acid was added to the initial gold sulfite complex solution. When complex $\mathrm{Na}_{3}\left[\mathrm{Au}\left(\mathrm{SO}_{3}\right)_{2}\right]$ and HF dissolve in water, they dissociate into cations and anions, including $\mathrm{Au}^{3+}$, 

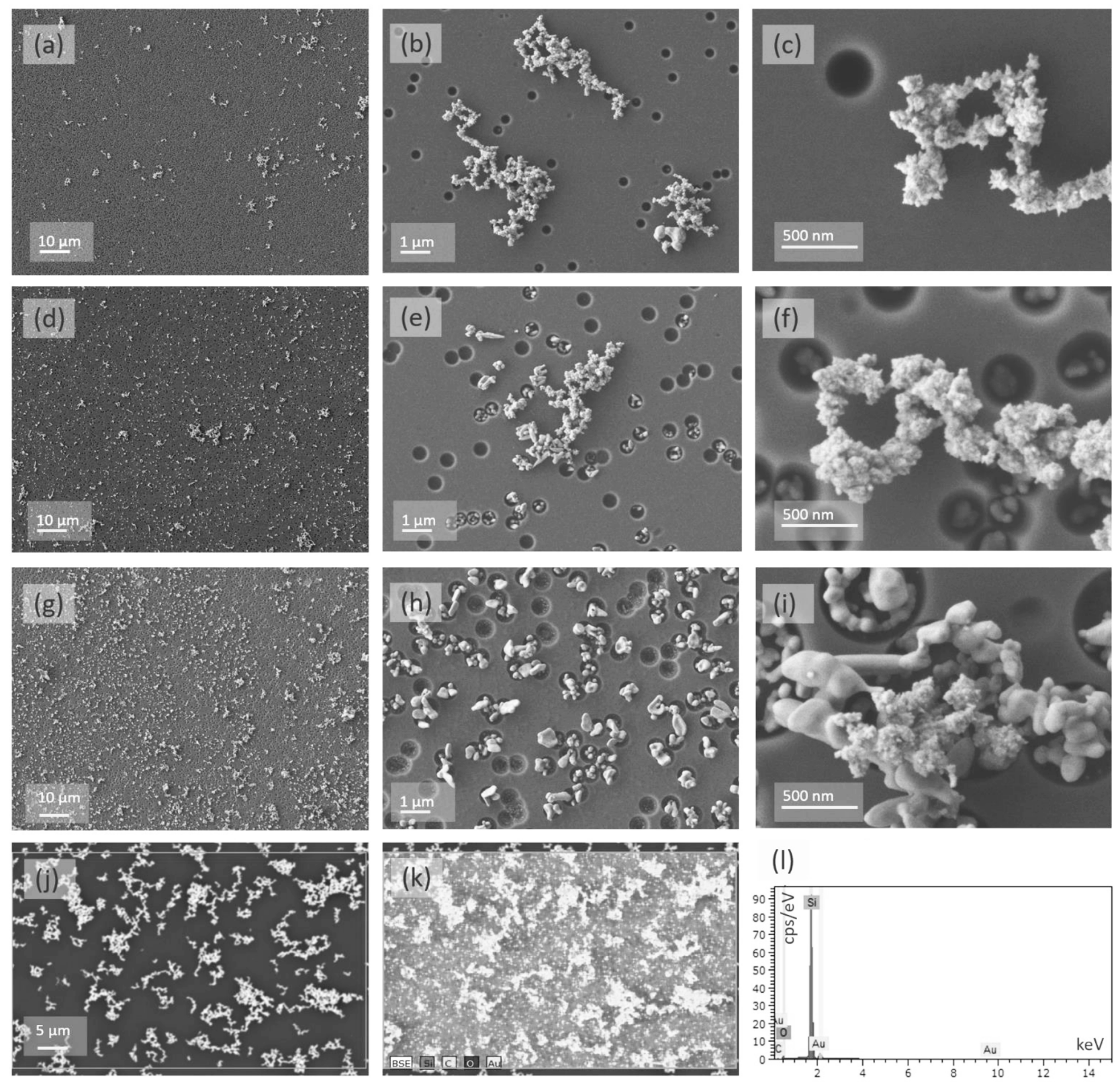

Fig. 1. SEM images of gold NSs on the $\mathrm{SiO}_{2} / \mathrm{Si}$ template deposited from the gold sulfite complex solution at different temperatures: $(\mathrm{a}, \mathrm{b}, \mathrm{c}) 50^{\circ} \mathrm{C}$; (d, e, f) $25^{\circ} \mathrm{C} ;(\mathrm{g}, \mathrm{h}, \mathrm{i}, \mathrm{j}) 0^{\circ} \mathrm{C}$; (k) EDX-map corresponding to the SEM image $(\mathrm{j})$ in the gold detection mode; (l) EDX spectrum of the corresponding region.

$\mathrm{H}^{+}$andF-, which participatein thefollowingchemical reactions:

$$
\begin{aligned}
& 4 \mathrm{Au}^{+}+\mathrm{Si}+6 \mathrm{~F}^{-} \rightarrow 4 \mathrm{Au}+\mathrm{SiF}_{6}^{2-}, \\
& \mathrm{SiO}_{2}+6 \mathrm{HF} \rightarrow \mathrm{H}_{2} \mathrm{SiF}_{6}+2 \mathrm{H}_{2} \mathrm{O} .
\end{aligned}
$$

From the analysis of chemical reactions $(1,2)$, it is obvious that the deposition of gold into the pores should occur with three simultaneous processes: electrochemical reduction of gold on silicon (1) with a simultaneous anodic process, Si passivation in acidic media to form a thin layer of $\mathrm{SiO}_{2}$, and $\mathrm{SiO}_{2}$ etching in hydrofluoric acid (2). This denotes the silicon surface activation by hydrofluoric acid. Electrons, participating in the reduction of gold cations to the metallic state in the electrolyte, are released from the silicon surface. The implementation of the processes near the silicon substrate will facilitate the selective metal deposition into the pores of the $\mathrm{SiO}_{2} / \mathrm{Si}$-template.

During the deposition from the gold sulfite complex without the addition of HF, the metal practically did not react at $50^{\circ} \mathrm{C}$, and its amount 
was excessive at $0^{\circ} \mathrm{C}$. Consequently for a better control of the process $25^{\circ} \mathrm{C}$ temperature was chosen for the deposition. The results of precipitation are shown in Fig. 2.

When dissolved in water, $\mathrm{AuCl}_{3}$ and $\mathrm{HF}$ dissociate into cations and anions $\mathrm{Au}^{3+}, \mathrm{Cl}^{-}, \mathrm{H}^{+}, \mathrm{F}^{-}$, which participate in subsequent chemical reac-

(a)
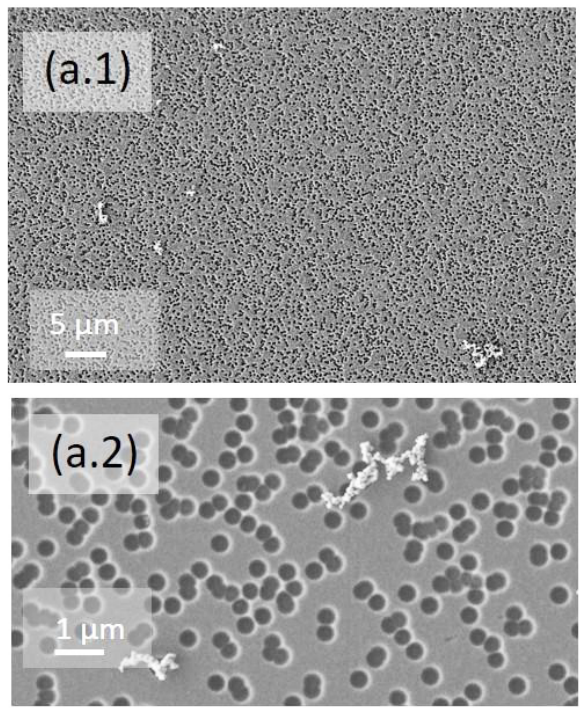

(a.3)

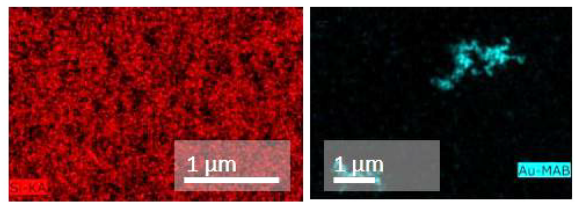

(c)
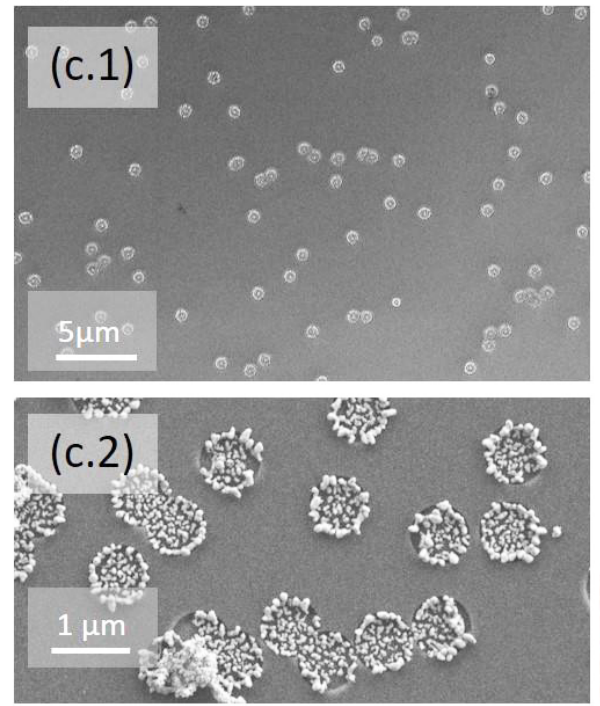

tions, schematically represented in Fig. 3(a). During the gold deposition in the pores, three processes simultaneously proceed: electrochemical reduction of gold on silicon with a simultaneous flow of anodic and cathodic processes, oxidation of silicon and etching of $\mathrm{SiO}_{2}$ in fluorine acid (Fig. 3(a)).

(b)

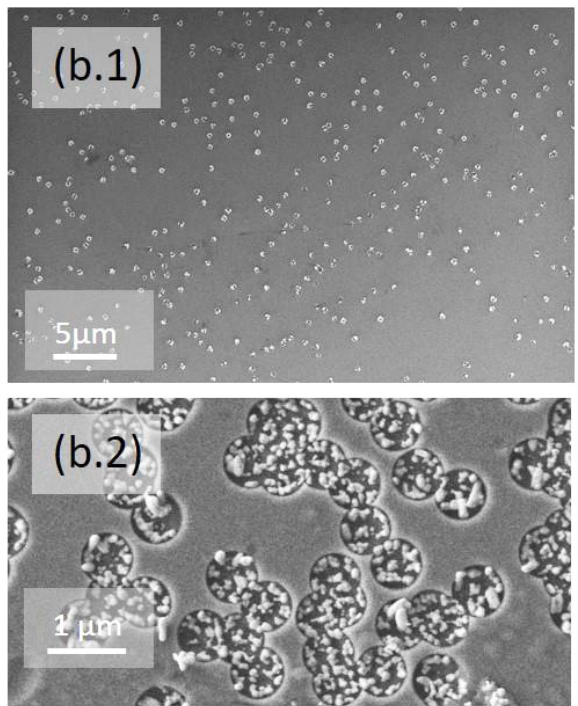

(b.3)

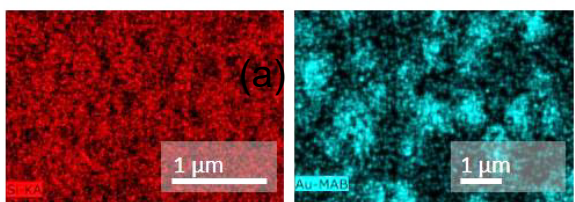

(c.3)

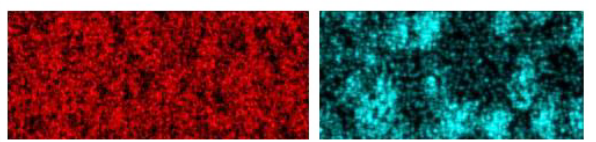

Fig. 2. SEM images of gold NSs from the complex $\mathrm{Na}_{3}\left[\mathrm{Au}\left(\mathrm{SO}_{3}\right)_{2}\right]$ and $\mathrm{HF}$ on the $\mathrm{SiO}_{2} / \mathrm{Si}$ template deposited at various temperatures: (a.1, a.2) $50^{\circ} \mathrm{C}$; (b.1, b.2) $25^{\circ} \mathrm{C}$; (c.1, c.2) $0^{\circ} \mathrm{C}$; (a.3-c.3) their EDX-map corresponding to the SEM image (j) in the gold and silica detection mode, respectively. 


$$
\begin{array}{lcc}
\text { Reduction } & \text { Etching } & \text { Oxidation } \\
4 \mathrm{Au}^{3+}+3 \mathrm{Si}+18 \mathrm{~F}^{-} \rightarrow 4 \mathrm{Au}+3 \mathrm{SiF}_{6}^{2-} & \mathrm{Si}+2 \mathrm{H}_{2} \mathrm{O} \rightarrow \mathrm{SiO}_{2}+4 \mathrm{H}^{+}+4 \mathrm{e}^{-} & \mathrm{SiO}_{2}+6 \mathrm{HF} \rightarrow \mathrm{H}_{2} \mathrm{SiF}_{6}+2 \mathrm{H}_{2} \mathrm{O} \\
& \mathrm{Si}+2 \mathrm{H}_{2} \mathrm{O} \stackrel{\mathrm{HCI}}{\longrightarrow} \mathrm{SiO}_{2}+2 \mathrm{H}_{2} & \mathrm{Si}+6 \mathrm{HF} \rightarrow \mathrm{H}_{2} \mathrm{SiF}_{6}+4 \mathrm{H}^{+}+4 \mathrm{e}^{-} \\
& &
\end{array}
$$

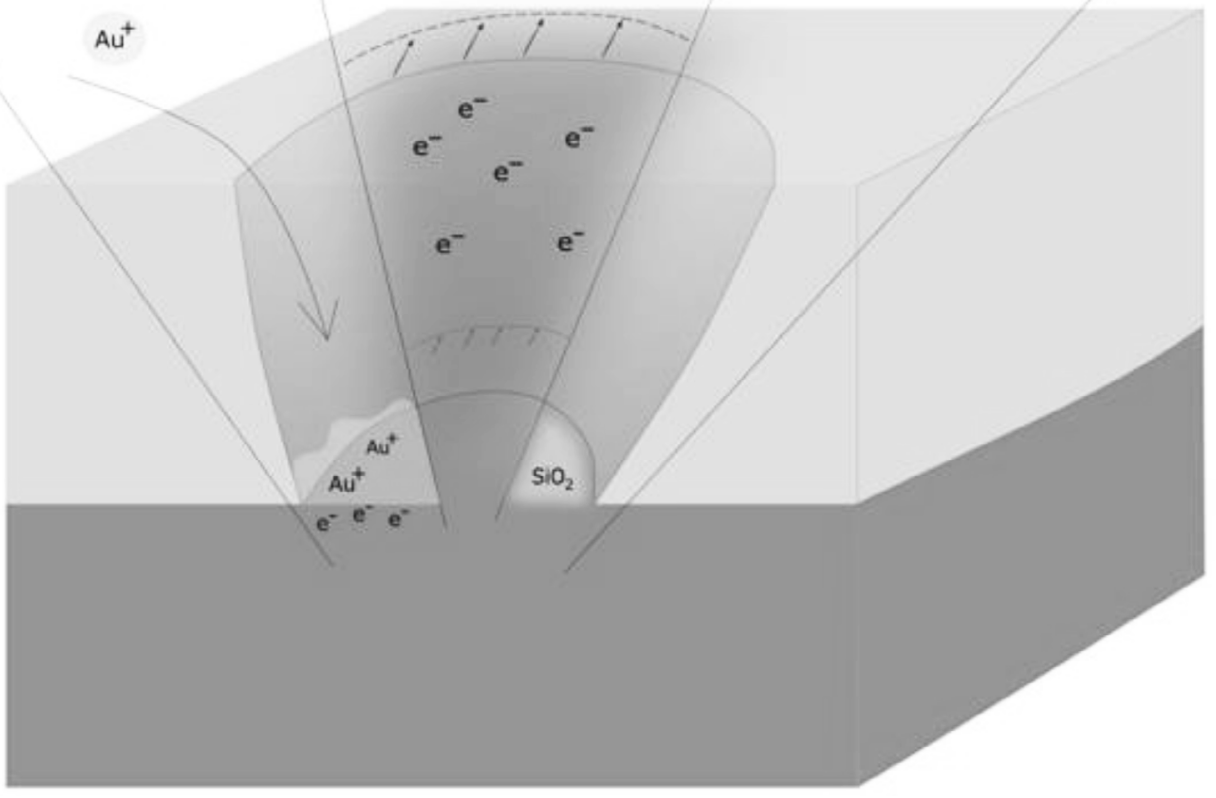

(b)

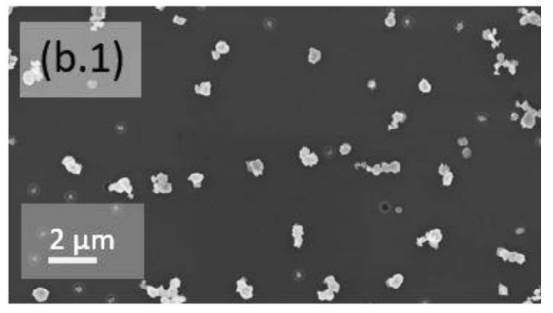

\section{(b.2)}
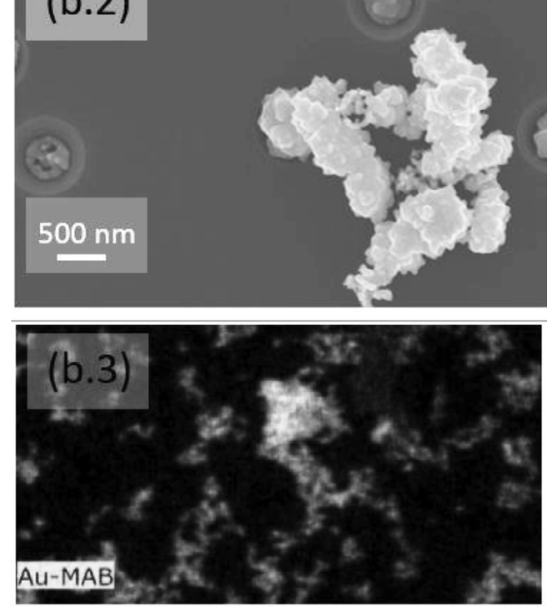

(c)
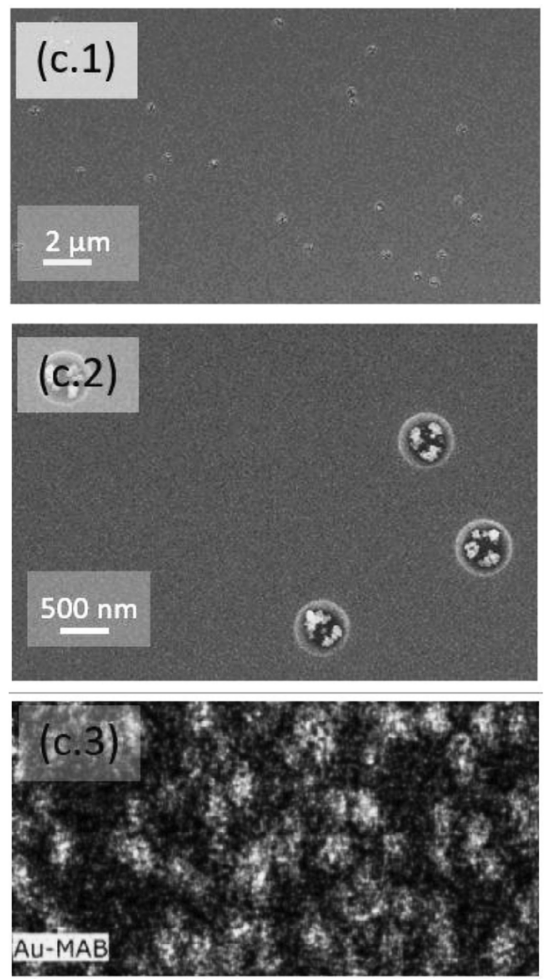

(d)
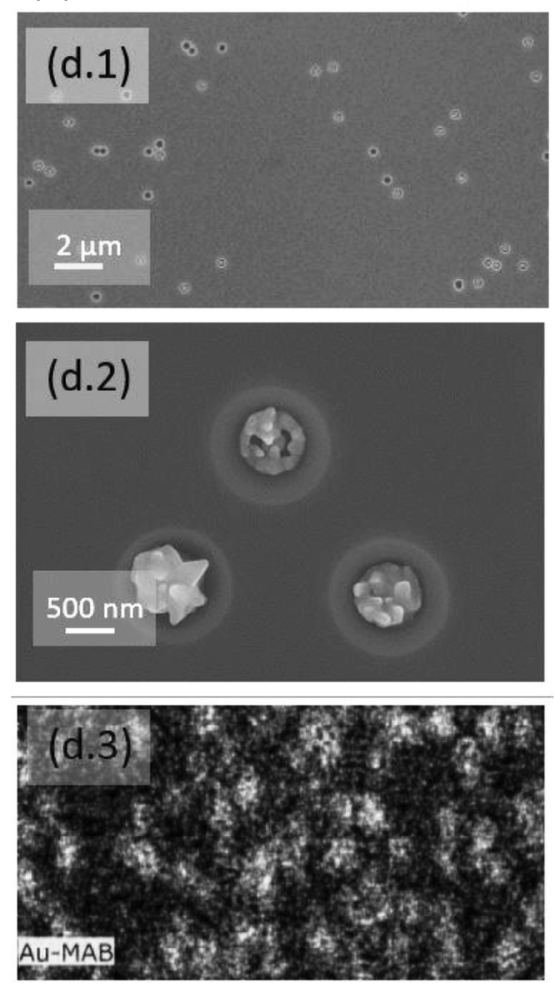

Figs. 3(b)-(d) show the SEM images of 'in-between' shape structures (nanoparticles obtained at different deposition temperatures) obtained from the reaction solution of gold chloride, showing the morphological evolution of Au nanoparticles using different concentrations of hydrofluoric acid (1,2.5 and 5\%). Au nanoparticles begin to form along the lateral faces of the pore, turning into nanostructures of complex morphology with pointed tips (Fig. 3(d)). The change in shape and size indicates different rates of deposition with temperature, using different concentrations of hydrofluoric acid. 


\section{Conclusions}

Series of experiments on the deposition of gold nanostructures into the pores of the $\mathrm{SiO}_{2} / \mathrm{Si}$ ion-track template were carried out. It was shown that, during deposition from a gold sulfite complex, gold nanostructures were synthesized both in the silicon oxide layer pores and on the $\mathrm{SiO}_{2}$ surface. It was demonstrated that the addition of a $5 \mathrm{M}$ hydrofluoric acid solution to a gold sulfite complex solution stimulated the selective deposition of gold nanostructures in the $\mathrm{SiO}_{2}$ template pores without gold deposit formation on the $\mathrm{SiO}_{2}$ surface. In addition to gold, sodium-containing crystals were observed in some places on the template surface. This fact requires additional studies. The method is also proposed for the precipitation of gold chloride from a solution through the addition of hydrofluoric acid with processes of oxidation, etching and reduction, including substitution, between gold chloride and $-\mathrm{OH}$ groups on the defective portions of the silicon dioxide surface.

The sample regions, which have exclusively gold nanostructures in the template pores, can be interesting for SERS application.

\section{Acknowledgements}

This work was supported by the Russian Foundation for Basic Research (Project No. 19-32-50058), the International Nanotechnology Innovation Center of the CIS (Grant Agreement No. 02-103) and H2020-MSCA-RISE2017-778308-SPINMULTIFILM Project.

\section{References}

[1] A.D. Maynard, R.J. Aitken, T. Butz, V. Colvin, K. Donaldson, G. Oberdörster, M.A. Philbert, J. Ryan, A. Seaton, V. Stone, S.S. Tinkle, L. Tran, N.J. Walker, and D.B. Warheit, Safe handling of nanotechnology, Nature 444, 267-269 (2006).

[2] E. Lindquist, K.N. Mosher-Howe, and X. Liu, Nanotechnology ... What is it good for? (Absolutely everything): A problem definition approach, Rev. Policy Res. 27, 255-271 (2010).

[3] B. Sharma, R.R. Frontiera, A.-I. Henry, E. Ringe, and R.P. Van Duyne, SERS: Materials, applications, and the future, Mater. Today 15, 16-25 (2012).
[4] Y. Xia and N.J. Halas, Shape-controlled synthesis and surface plasmonic properties of metallic nanostructures, MRS Bull. 30, 338-348 (2005).

[5] J. Langer, S.M. Novikov, and L.M. Liz-Marzán, Sensing using plasmonic nanostructures and nanoparticles, Nanotechnology 26, 322001 (2015).

[6] H.J. Yin, Z.Y. Chen, Y.M. Zhao, M.Y. Lv, C.A. Shi, Z.L. Wu, X. Zhang, L. Liu, M.L. Wang, and H.J. Xu, Ag@Au core-shell dendrites: A stable, reusable and sensitive surface enhanced Raman scattering substrate, Sci. Rep. 5, 1-9 (2015).

[7] K. Girel, E. Yantcevich, G. Arzumanyan, N. Doroshkevich, and $\mathrm{H}$. Bandarenka, Detection of DNA molecules by SERS spectroscopy with silvered porous silicon as an active substrate, Phys. Status Solidi 213, 2911-2915 (2016).

[8] H. Wei and $\mathrm{H}$. Xu, Hot spots in different metal nanostructures for plasmon-enhanced Raman spectroscopy, Nanoscale 5, 10794-10805 (2013).

[9] E.Kaniukov, A.Shumskaya, D.Yakimchuk, A.Kozlovskiy, I. Korolkov, M. Ibragimova, M. Zdorovets, K. Kadyrzhanov, V. Rusakov, M. Fadeev, E. Lobko, K. Saunina, and L. Nikolaevich, FeNi nanotubes: perspective tool for targeted delivery, Appl. Nanosci. 9, 835-844 (2019).

[10]A.L. Kozlovskiy, D.I. Shlimas, A.E. Shumskaya, E.Y. Kaniukov, M.V. Zdorovets, and K.K. Kadyrzhanov, Influence of electrodeposition parameters on structural and morphological features of Ni nanotubes, Phys. Met. Metallogr. 118, 164169 (2017).

[11]P. Apel, Swift ion effects in polymers: industrial applications, Nucl. Instrum. Methods Phys. Res. B 208, 11-20 (2003).

[12]A.E. Shumskaya, E.Y. Kaniukov, A.L. Kozlovskiy, D.I. Shlimas, M.V. Zdorovets, M.A. Ibragimova, V.S. Rusakov, and K.K. Kadyrzhanov, Template synthesis and magnetic characterization of $\mathrm{FeNi}$ nanotubes, Prog. Electromagn. Res. C 75, 23-30 (2017).

[13]D. Fink, A.V. Petrov, K. Hoppe, W.R. Fahrner, R.M. Papaleo, A.S. Berdinsky, A. Chandra, A. Chemseddine, A. Zrineh, A. Biswas, F. Faupel, and L.T. Chadderton, Etched ion tracks in silicon oxide and silicon oxynitride as charge injection or extraction channels for novel electronic 
structures, Nucl. Instrum. Methods Phys. Res. B 218, 355-361 (2004).

[14]E.Y. Kaniukov, D.V. Yakimchuk, V.D. Bundyukova, A.E. Shumskaya, A.A. Amirov, and S.E. Demyanov, Peculiarities of charge transfer in $\mathrm{SiO}_{2}$ (Ni)/Si nanosystems, Adv. Condens. Matter Phys. 2018, 1-8 (2018).

[15]E.Y. Kaniukov, A.L. Kozlovsky, D.I. Shlimas, M.V.Zdorovets, D.V. Yakimchuk, E.E. Shumskaya, and K.K. Kadyrzhanov, Electrochemically deposited copper nanotubes, J. Surf. Invest. X-ray Synchrotron Neutron Tech. 11, 270-275 (2017).

[16]E. Kaniukov, D. Yakimchuk, G. Arzumanyan, H. Terryn, K. Baert, A. Kozlovskiy, M. Zdorovets, E. Belonogov, and S. Demyanov, Growth mechanisms of spatially separated copper dendrites in pores of a $\mathrm{SiO}_{2}$ template, Philos. Mag. 97, 22682283 (2017).

[17]V. Sivakov, E.Y. Kaniukov, A.V. Petrov, O.V. Korolik, A.V. Mazanik, A. Bochmann, S. Teichert, I.J. Hidi, A. Schleusener, D. Cialla, M.E. ToimilMolares, C. Trautmann, J. Popp, and S.E. Demyanov, Silver nanostructures formation in porous $\mathrm{Si} / \mathrm{SiO}_{2}$ matrix, J. Cryst. Growth 400, 21-26 (2014).

[18]D. Yakimchuk, E. Kaniukov, V. Bundyukova, L. Osminkina, S. Teichert, S. Demyanov, and V. Sivakov, Silver nanostructures evolution in porous $\mathrm{SiO}_{2} / \mathrm{p}$-Si matrices for wide wavelength surface-enhanced Raman scattering applications, MRS Commun. 8, 95-99 (2018).

[19]K.H. Su, Q.H. Wei, X. Zhang, J.J. Mock, D.R. Smith, and S. Schultz, Interparticle coupling effects on plasmon resonances of nanogold particles, Nano Lett. 3, 1087-1090 (2003).

[20]F.H.Cho, Y.C.Lin, and Y.H.Lai, Electrochemically fabricated gold dendrites with high-index facets for use as surface-enhanced Raman-scattering- active substrates, Appl. Surf. Sci. 402, 147-153 (2017).

[21]J. Fang, X. Ma, H. Cai, X. Song, and B. Ding, Nanoparticle-aggregated 3D monocrystalline gold dendritic nanostructures, Nanotechnology 17, 5841-5845 (2006).

[22]A. Mashentseva, D. Borgekov, M. Zdorovets, and A. Russakova, Synthesis, structure, and catalytic activity of $\mathrm{Au} /$ poly(ethylene terephthalate) composites, Acta Phys. Pol. A 125, 1263-1267 (2014).

[23]A.A. Mashentseva, D.B. Borgekov, D.T. Niyazova, and M.V. Zdorovets, Evaluation of the catalytic activity of the composite track-etched membranes for $p$-nitrophenol reduction reaction, Pet. Chem. 55, 810-815 (2015).

[24]E.Y. Kaniukov, J. Ustarroz, D.V. Yakimchuk, M. Petrova, H. Terryn, V. Sivakov, and A.V. Petrov, Tunable nanoporous silicon oxide templates by swift heavy ion tracks technology, Nanotechnology 27, 115305 (2016).

[25]D. Yakimchuk, V. Bundyukova, A. Smirnov, and E. Kaniukov, Express method of estimation of etched ion track parameters in silicon dioxide template, Phys. Status Solidi B Basic Solid State Phys. 256, 1800316 (2018).

[26]V. Bundyukova, D. Yakimchuk, E. Shumskaya, A. Smirnov, M. Yarmolich, and E. Kaniukov, Post-processing of $\mathrm{SiO}_{2} / \mathrm{Si}$ ion-track template images for pores parameters analysis, Mater. Today Proc. 7, 828-834 (2019).

[27]V. Bundyukova, E. Kaniukov, A. Shumskaya, A. Smirnov, M. Kravchenko, and D. Yakimchuk, Ellipsometry as an express method for determining the pore parameters of ion-track $\mathrm{SiO}_{2}$ templates on a silicon substrate, EPJ Web Conf. 201, 01001 (2019).

\section{AUKSO NANODARINIŲ SINTEZĖ SiO/Si MATRICOJE NAUDOJANT ŠLAPIĄ CHEMINI NUSODINIMA}

V.D. Bundyukova a , D.V. Yakimchuk ${ }^{\text {a }}$, A. Kozlovskiy ${ }^{\text {b, c }}$, D.I. Shlimas ${ }^{\text {b,c }}$, D.I. Tishkevich a,d, E.Yu. Kaniukov ${ }^{\mathrm{e}}$

\footnotetext{
${ }^{a}$ Baltarusijos nacionalinés moksly akademijos Mokslinis-praktinis medžiagu tyrimo centras, Minskas, Baltarusija

${ }^{\mathrm{b}}$ Branduolinès fizikos instituto Kietojo kūno fizikos laboratorija, Astana, Kazachstanas

${ }^{c}$ L. N. Gumiliovo vardo Eurazijos nacionalinis universitetas, Astana, Kazachstanas

d Pietu Uralo valstybinis universitetas, Čeliabinskas, Rusija

${ }^{\mathrm{e}}$ Baltarusijos nacionalinés mokslų akademijos Naujų medžiagų chemijos institutas, Minskas, Baltarusija
} 